\title{
Effect of sulphur supplementation on intake, digestibility and microbiological changes in the rumen of goats
}

\author{
L Gutiérrez, D Contreras, JT Ramirez \\ Universidad de Colima, Facultad de Medicina Veterinaria y Zootecnia, Apartado postal $n^{\circ} 36$, \\ 28100 Tecoman, Colima. Mexico
}

The efficacy of sulphur supplementation when ruminants are fed poorly digestible fibrous material is dependent to some extent on the effects upon the ecology of the microorganisms inhabiting the rumen-reticulum.

Eight male goats were each fitted with a rumen cannula. Over a period of 14 days, the animals were introduced to a diet of corn stubble $(84.5 \% \mathrm{OM}, 5.9 \% \mathrm{CP}$ and $206 \mathrm{ppm}$ $\mathrm{S}$ ), and urea $11 \mathrm{~g} / \mathrm{d}$, sodium sulphate $2.5 \mathrm{~g} / \mathrm{d}$, and a mineral mix without sulphur as supplement. Considering the sulphur contained in the corn stubble, the nitrogen-sulphur ratio was $16.2: 1$.

Sulphur supplementation caused an increase of $235.3 \mathrm{~g} / \mathrm{d}$ in the OM intake, and $44 \mathrm{ml} / \mathrm{d}$ in water intake. The sulphur improved live weight gains from -52.5 to $12.5 \mathrm{~g} / \mathrm{d}$.

The apparent digestibility of OM was also increased by sulphur supplementation from $26.9 \%$ to $37.2 \%$. The results showed that sulphur fed caused large increases in the DM disappearance of corn stubble from nylon bags in $12,24,36$ and $48 \mathrm{~h}$.

Sulphur supplementation increased of all three rumen microbial groups, but the most dramatic increase was observed at $24 \mathrm{~h}$ in the number of sporangial forms of rumen anaerobic fungi.

The results suggest that sulphur may improve ruminant production by stimulating the activity of rumen micro-organisms, especially those playing a role in degrading fibrous forages with large amount of lignocellulose.
Parameters

Without supplementation

DM disappearance from nylon bags (\%)

$12 \mathrm{~h}$

$24 \mathrm{~h}$

16.0

21.0

$36 \mathrm{~h}$

28.5

$48 \mathrm{~h}$

39.0

Rumen anaerobic fungi (sporangia $/ \mathrm{mm}^{2}$ )

$\begin{array}{lcc}24 \mathrm{~h} & 35.0 & (5.64) \\ 48 \mathrm{~h} & 10.0 & (2.14) \\ \text { cteria }(\times 109 / \mathrm{ml}) & 0.2 & (0.01) \\ \text { tozoa }\left(\times 10^{3} / \mathrm{ml}\right) & 0.5 & (0.04)\end{array}$

Protozoa (x 103/ml)

0.2

$(0.04)$

\section{Sulphur supplementation}

27.5

42.9

49.1

52.2

153.0

45.7

1.5

1.6

(0.15)

Standard error in parentheses. 